\title{
Commentary: Arnica Montana Effects on Gene Expression in a Human Macrophage Cell Line: Evaluation by Quantitative Real-Time PCR
}

\author{
Salvatore Chirumbolo ${ }^{1 *}$ and Geir Bjørklund ${ }^{2}$ \\ ${ }^{1}$ Unit of Geriatry, Department of Medicine, University of Verona, Verona, Italy, ${ }^{2}$ Council for Nutritional and Environmental \\ Medicine, Mo i Rana, Norway
}

Keywords: Arnica, homeopathy, gene expression profiling, inflammation, sesquiterpenes

\section{A commentary on}

Arnica montana Effects on Gene Expression in a Human Macrophage Cell Line. Evaluation by Quantitative Real-Time PCR

OPEN ACCESS

Edited by:

Pietro Ghezzi,

University of Brighton, UK

Reviewed by:

Charles Dinarello,

University of Colorado Denver, USA

Surendra P. Verma,

National Autonomous University of

Mexico, Mexico

*Correspondence:

Salvatore Chirumbolo

salvatore.chirumbolo@univr.it

Specialty section:

This article was submitted to Inflammation,

a section of the journa

Frontiers in Immunology

Received: 04 June 2016

Accepted: 12 July 2016 Published: 08 September 2016

Citation:

Chirumbolo S and Bjørklund G (2016) Commentary: Arnica Montana Effects

on Gene Expression in a Human

Macrophage Cell Line: Evaluation by

Quantitative Real-Time PCR.

Front. Immunol. 7:280.

doi: 10.3389/fimmu.2016.00280 by Olioso D, Marzotto M, Bonafini C, Brizzi M, Bellavite P. Homeopathy (2016) 105(2):131-47. doi: 10.1016/j.homp.2016.02.001

Olioso et al. described the effect of Arnica montana L on the gene expression of the human monocytic leukemia cell line THP-1, reporting that homeopathic preparations of Arnica upregulated the expression of genes, such as CCL7, CXCL1, CXCL2, interleukin 8, and bone morphogenetic protein 2 (BMP2) (1). Plants from the genus Arnica are sources of anti-inflammatory compounds and homeopathic formulations were reported to be effective in treating inflammatory ailments (2-4), despite some negative or controversial evidence $(5,6)$. Olioso et al. showed effects of Arnica homeopathic preparations from $2 \mathrm{c}$ to $15 \mathrm{c}$, on the gene expression of several cytokines and chemokines, involved in the recruitment and activation of neutrophils and other innate immune cells using a qRT-PCR (1). Bioactive components from the disk flowers of Arnica species are sesquiterpene lactones, e.g., chamissonolid, helenalin, and 11 $\alpha, 13$-dihydrohelenalin (7-9). The concentration of these molecules in Arnica homeopathic preparations was not chemically defined, apart from the evaluation as $0.036 \%$ sesquiterpene lactones in the raw alcoholic extract (1). Usually, the amount of total helenalin and total $11 \alpha, 13$-dihydrohelenalin is $5.6 \%$, i.e., $1.1 \mathrm{mg}$ and $5.1 \%$, i.e., $1.0 \mathrm{mg}$, respectively (10). This would mean that in the starting $30 \%$ alcoholic preparation of Arnica (1c), a percentage of $0.036 \%$ sesquiterpene lactones, should correspond to $0.72 \mu$ g, i.e., $72 \mathrm{pg}$ in the dilution $2 c(1)$, quite far from the activity range reported elsewhere $(9,10)$. Surprisingly, Olioso et al. reported an activity on NF- $\kappa \mathrm{B}$ gene expression in any dilution used (except for $15 \mathrm{c}$ ) only in cells treated $24 \mathrm{~h}$ and activated with IL-4. Aside for the upregulation of rela-A gene at $2 \mathrm{~h}$, Olioso et al. did not show any effect of Arnica preparation 2c, despite the existence of further reports published elsewhere showing an effect of sesquiterpene lactones on NF- $\kappa B(11,12)$. The authors did not report reproducible data for the highest concentrated dilution used in their study, i.e., Arnica 2c, which appeared to exhibit a significant action quite only on THP-1 cell line following activation with IL-4 [Table 3B in Ref. (1)]. They did not ascertain the absence of outlying observations in the experimental data. It is mandatory that, before calculating the central tendency and dispersion parameters based on the outlier-based indicators (e.g., mean, SD, SEM), the data should be subjected to the discordancy tests (13-16). Showing only SEM or other parameters excluding raw data cannot 


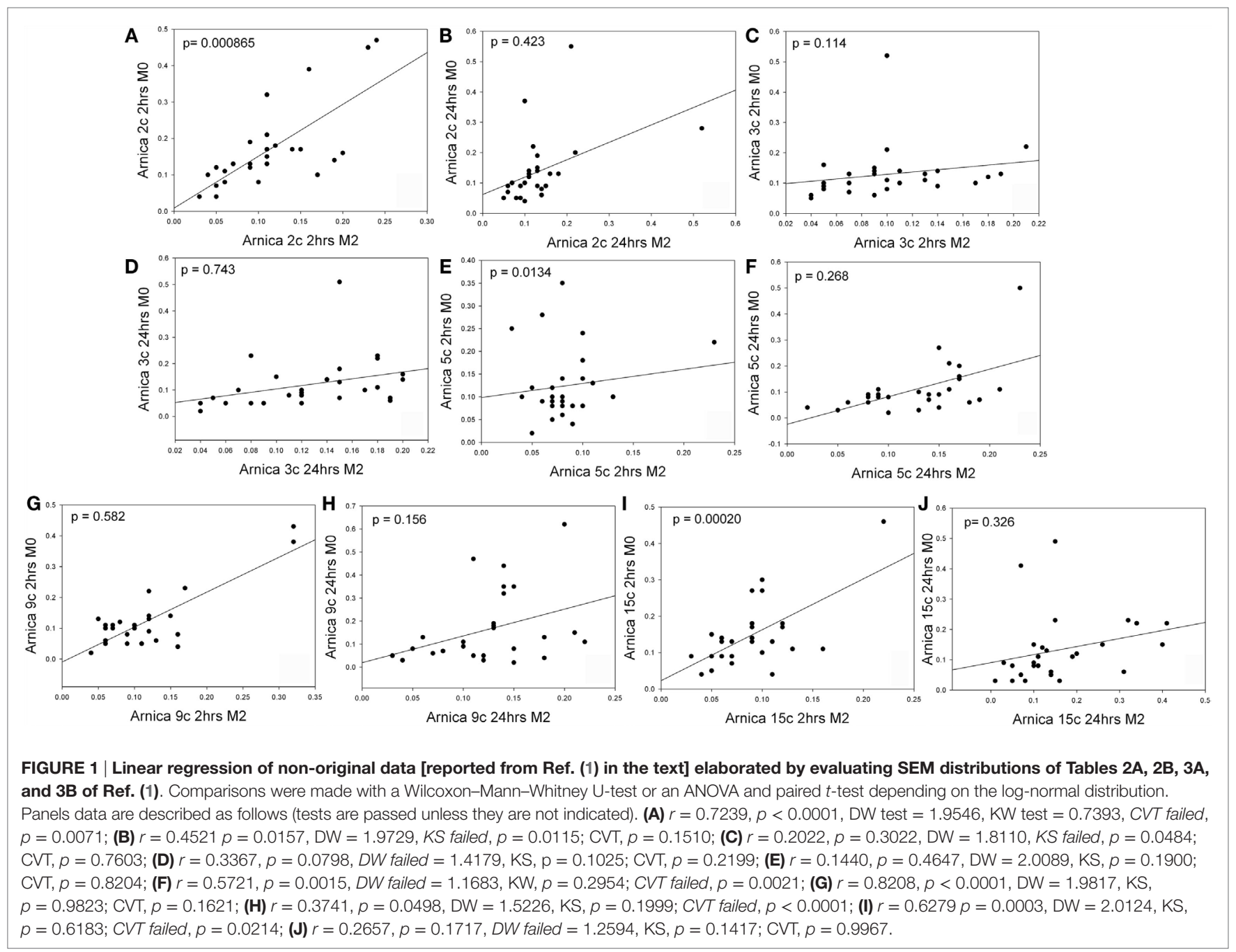

allow the reader to realize about any statistical reliability and reproducibility. More importantly, the $95 \%$ confidence limits of the mean values [Table 2A in Ref. (1)] are not distinguishable from zero implying no effect.

We evaluated statistic distribution of SEM variability to ascertain if any reported outliers due to bias error affected the parametric or non-parametric behavior of the investigated samples. The authors used Wilcoxon test, although no special requirements to call for a non-parametric test were requested (17). Effects reported as changes $p<0.05$ in the gene expression pattern amounted to 4 and 7 ( 2 and $24 \mathrm{~h}$, respectively, M0) and to 8 and 12 ( 2 and $24 \mathrm{~h}$, respectively) for THP-1 monocytes treated with IL-4 (M2-type), where $p<0.01$ where 13 (M2) vs. 4 (M0) (1). Probably, cells undergoing less stress $\left(24 \mathrm{~h}\right.$ incubation at $37^{\circ} \mathrm{C} 5 \%$ $\mathrm{CO}_{2}$ ) and addressed to drive any molecular machinery to a highly controlled response to a stimulus (i.e., IL-4) amplified signals vs. noises, i.e., reduced the difference between noises and statistical variability.

A statistical analysis of the reported data in Tables $2 \mathrm{~A}, 2 \mathrm{~B}, 3 \mathrm{~A}$, and $3 \mathrm{~b}$ of Ref. (1) showed that intra-assay and inter-assay variability, expressed as SEM, contained possible bias (heterogeneous variance) due to the dispersion effect of the reported variability and outlying data. In this context, SEMs appeared to have been log-normally distributed, as evaluated in a goodness-of-fit test, with some exception, particularly in experiments where THP-1 followed the IL-4 treatment (Cramer-von Mises test: $2 c$, $p=0.676 ; 3 c, p=0.279: 5 c, p=0.254 ; 9 c, p=0.792$. Data were confirmed in a Kolmogorov-Smirnov test and the Shapiro-Wilk test, and only the D'Agostino-Pearson test gave $15 c, p=0.07$ ) (18). A possible carry over effect on SEM was caused by data containing outliers. Only one or two outlying observations were identified, especially by the more powerful Grubbs, skewness, and kurtosis discordancy tests (Dixon tests generally failed) (18). A Rosner's extreme studentized deviate test for multiple outliers (two-sided test, $z=3.5$ ), showed, respectively 18 and 14 outliers in the SEM distribution of M0-type TPH-1 cell line and 4 and 0 for SEM distribution in M2-type THP-1 cell line, confirming a more constant dynamics of gene expression in M2-cells $(1,19)$. Outliers in the SEM columns probably biased any statistic significance, as variability in the elaborated data was heterogeneously dispersed. The Dixon's Q-test for single outlier detection showed that the most of outliers occurred in the evaluation of CCL7 gene 
expression in the M0 experimental group $(2 \mathrm{~h}: 3 \mathrm{c}, p<0.002 ; 9 \mathrm{c}$, $p=0.004 ; 15 \mathrm{c}, p=0.022 ; 24 \mathrm{~h}: 2 \mathrm{c}, p=0.003 ; 3 \mathrm{c}, p=0.002 ; 5 \mathrm{c}$, $p=0.002 ; 15 c, p=0.002$ ), while in the M2 group they occurred only in the $2 \mathrm{~h}$ cluster (5c CCL17, $p<0.002$; 9c CCL2, CCL5, $p<0.05$; 15c CCL7, $p<0.04)(1)$, results confirmed with Grubbs' test (20). Although the authors showed skewness (1), variance heterogeneity might affect the decision about which test should adopt.

Figure 1 reports that this difference, calculated between each gene for each dilution, appeared significant only in the $2 \mathrm{~h}$ group (2c, $p=0.000865 ; 5 c, p=0.0134,15 c, p=0.00020$ ) but also that regression data for the other comparisons contained some bias, regarding either normal fit, Durbin-Watson test or the constant variance test $(C V T)(1,19)$. The presence of discordant outliers in bivariate data should enforce our conclusion $(13,21,22)$.

Statistic significance appeared as highly frequent in a more stable experimental condition and in dilutions with active principles very far from a pharmacological bioactivity and without an

\section{REFERENCES}

1. Olioso D, Marzotto M, Bonafini C, Brizzi M, Bellavite P. Arnica montana effects on gene expression in a human macrophage cell line. Evaluation by quantitative real-time PCR. Homeopathy (2016) 105(2):131-47. doi:10.1016/j. homp.2016.02.001

2. Iannitti T, Morales-Medina JC, Bellavite P, Rottigni V, Palmieri B. Effectiveness and safety of Arnica montana in post-surgical setting, pain and inflammation. Am J Ther (2016) 23(1):e184-97. doi:10.1097/MJT.0000000000000036

3. Seeley BM, Denton AB, Ahn MS, Maas CS. Effect of homeopathic Arnica montana on bruising in face-lifts: results of a randomized, double-blind, placebo-controlled clinical trial. Arch Facial Plast Surg (2006) 8(1):54-9. doi:10.1001/archfaci.8.1.54

4. Fioranelli M, Bianchi M, Roccia MG, DI Nardo V. Effects of Arnica comp.Heel $^{*}$ on reducing cardiovascular events in patients with stable coronary disease. Minerva Cardioangiol (2016) 64(1):34-40.

5. Kotlus BS, Heringer DM, Dryden RM. Evaluation of homeopathic Arnica montana for ecchymosis after upper blepharoplasty: a placebo-controlled, randomized, double-blind study. Ophthal Plast Reconstr Surg (2010) 26(6):395-7. doi:10.1097/IOP.0b013e3181cd93be

6. Ho D, Jagdeo J, Waldorf HA. Is there a role for Arnica and bromelain in prevention of post-procedure ecchymosis or edema? A systematic review of the literature. Dermatol Surg (2016) 42(4):445-63. doi:10.1097/ DSS.0000000000000701

7. Klaas CA, Wagner G, Laufer S, Sosa S, Della Loggia R, Bomme U, et al. Studies on the anti-inflammatory activity of phytopharmaceuticals prepared from Arnica flowers. Planta Med (2002) 68(5):385-91. doi:10.1055/s-2002-32067

8. Kos O, Lindenmeyer MT, Tubaro A, Sosa S, Merfort I. New sesquiterpene lactones from Arnica tincture prepared from fresh flowerheads of Arnica montana. Planta Med (2005) 71(11):1044-52. doi:10.1055/s-2005-871284

9. Lyss G, Knorre A, Schmidt TJ, Pahl HL, Merfort I. The anti-inflammatory sesquiterpene lactone helenalin inhibits the transcription factor NF-kappaB by directly targeting p65. J Biol Chem (1998) 273(50):33508-16. doi:10.1074/ jbc. 273.50 .33508

10. Staneva J, Denkova P, Todorova M, Evstatieva L. Quantitative analysis of sesquiterpene lactones in extract of Arnica montana L. by $1 \mathrm{H}$ NMR spectroscopy. J Pharm Biomed Anal (2011) 54(1):94-9. doi:10.1016/j.jpba.2010.08.018

11. Lyss G, Schmidt TJ, Merfort I, Pahl HL. Helenalin, an anti-inflammatory sesquiterpene lactone from Arnica, selectively inhibits transcription factor NF-kappaB. Biol Chem (1997) 378(9):951-61. doi:10.1515/bchm.1997. 378.9.951

12. Jäger C, Hrenn A, Zwingmann J, Suter A, Merfort I. Phytomedicines prepared from Arnica flowers inhibit the transcription factors AP-1 and NF-kappaB and apparent dose-response behavior. Probably, not all the distributions should be evaluated with a Wilcoxon due to the existence of outliers much more frequent only in certain experimental conditions.

In conclusion, data arrays as presented by the authors may contain some discordant outlying observations, thus affecting results reliability. The effects of Arnica water/ethanol extracts should be, therefore, replicated.

Our consideration is that by replicating the data, we could appreciate if homeopathic Arnica is really effective on inflammatory gene upregulation in innate immune cells.

\section{AUTHOR CONTRIBUTIONS}

SC read the original paper, discussed it with GB, statistics were re-evaluated by SC with GB, GB gave insights from the literature, $\mathrm{SC}$ re-wrote the paper, GB revised it, and SC reviewed the revision and submitted the paper once GB has given his agreement.

modulate the activity of MMP1 and MMP13 in human and bovine chondrocytes. Planta Med (2009) 75(12):1319-25. doi:10.1055/s-0029-1185668

13. Barnett V, Lewis T. Outliers in Statistical Data. Chichester: John Wiley \& Sons (1994). 584 p.

14. Verma SP. Sixteen statistical tests for outlier detection and rejection in evaluation of international geochemical reference materials: example of microgabbro PM-S. Geostandards newsletter. J Geostand Geoanal (1997) 21(1):59-75. doi:10.1111/j.1751-908X.1997.tb00532.x

15. Verma SP. Geochemometrics. Rev Mex Cienc Geol (2012) 29(1):276-98.

16. Verma S, Díaz-González L. Application of the discordant outlier detection and separation system in the geosciences. Int Geol Rev (2012) 54(3):593-614. doi:10.1080/00206814.2011.569402

17. Verma SP. Monte Carlo comparison of conventional ternary diagrams with new log-ratio bivariate diagrams and an example of tectonic discrimination. Geochem J (2015) 49(4):393-412. doi:10.2343/geochemj.2.0364

18. Stocker RS IV, Adekpedjou A. Optimal goodness-of-fit tests for recurrent event data. Lifetime Data Anal (2011) 17(3):409-32. doi:10.1007/s10985-011-9193-1

19. Mollah MM, Jamal R, Mokhtar NM, Harun R, Mollah MN. A hybrid oneway ANOVA approach for the robust and efficient estimation of differential gene expression with multiple patterns. PLoS One (2015) 10(9):e0138810. doi:10.1371/journal.pone.0138810

20. Verma SP, Díaz-González L, Rosales-Rivera M, Quiroz-Ruiz A. Comparative performance of four single extreme outlier discordancy tests from Monte Carlo simulations. ScientificWorldJournal (2014) 2014:746451. doi:10.1155/2014/746451

21. Verma SP, Cruz-Huicochea R, Díaz-González L. Univariate data analysis system: deciphering mean compositions of island and continental arc magmas, and influence of underlying crust. Int Geol Rev (2013) 55(15):1922-40. doi:10.1080/00206814.2013.810363

22. Verma SP, Díaz-González L, Sánchez-Upton P, Santoyo E. OYNYL: a new computer program for ordinary, York, and New York least-squares linear regressions. WSEAS Trans Environ Dev (2006) 2(8):997-1002.

Conflict of Interest Statement: The authors declare that the research was conducted in the absence of any commercial or financial relationships that could be construed as a potential conflict of interest.

Copyright (c) 2016 Chirumbolo and Bjørklund. This is an open-access article distributed under the terms of the Creative Commons Attribution License (CC BY). The use, distribution or reproduction in other forums is permitted, provided the original author(s) or licensor are credited and that the original publication in this journal is cited, in accordance with accepted academic practice. No use, distribution or reproduction is permitted which does not comply with these terms. 